\title{
Torso, a receptor tyrosine kinase required for embryonic pattern formation, shares substrates with the Sevenless and EGF-R pathways in Drosophila
}

\author{
Helen J. Doyle and J. Michael Bishop \\ The G.W. Hooper Foundation, University of California, San Francisco, California 94143-0552 USA
}

\begin{abstract}
The maternally expressed Drosophila gene torso (tor) is a receptor tyrosine kinase that, when activated, initiates a signal transduction cascade that is responsible for the proper differentiation of the terminal, nonsegmented regions of the embryo. 1(1)pole hole, the Drosophila raf-1 serine-threonine kinase homolog, and corkscrew, a tyrosine phosphatase, have been shown previously to function in this signal transduction pathway. We have identified other products in this pathway by carrying out a mutagenesis screen for dominant suppressors of a tor gain-of-function allele. More than $\mathbf{4 0}$ mutations, some of which fall into seven complementation groups, have been characterized genetically. Two of these correspond to mutations in ras-1 and Son of sevenless (Sos), which also function in the sevenless and EGF receptor (Der) tyrosine kinase pathways. The phenotypes of several other $S u(t o r)$ mutations suggest that they also function in other receptor tyrosine kinase-activated pathways at different times during Drosophila development.
\end{abstract}

[Key Words: Torso; Drosophila receptor tyrosine kinase; signal transduction; suppressors]

Received December 18, 1992; accepted January 25, 1993.

During the development of most multicellular organisms, the determination of cell fate and subsequent differentiation require communication among cells, either over a distance or by direct cell-cell contact. Extracellular signals are often received and interpreted by signal transduction cascades that use a variety of proteins, such as kinases, phosphatases, and $\mathrm{G}$ proteins, many of which are functionally conserved over a wide range of species (Bourne et al. 1991; Greenwald and Rubin 1992; Pawson 1992). Given the complexity of signal transduction pathways, it is not surprising that certain mutations in pathway components are associated with cellular transformation and oncogenesis (Cantley et al. 1991), suggesting that these proteins are critical in the regulation of cell proliferation and/or differentiation.

A powerful tool for dissecting the different interactions in signaling pathways is to alter, by mutation, the activities of particular proteins. For these studies, systems in which genetics can be exploited have recently been very useful. In particular, the control of bud site selection in yeast, under the control of the BUD genes (Chant et al. 1991; Powers et al. 1991), and the induction of vulval cell fates during Caenorhabditis elegans development (Aroian et al. 1990; Beitel et al. 1990; Clark et al. 1992; Hill and Sternberg 1992; for review, see Greenwald and Rubin 1992; Sternberg and Horvitz 1992) are two pathways in which many members and their relation- ships are rapidly becoming better understood. In Drosophila, the signaling cascade regulated by the receptor tyrosine kinase, Sevenless $\{\mathrm{Sev}\}$, has also been studied extensively. Activation of Sev is required for the differentiation of one of the photoreceptor cells, R7, in the compound eye (for review, see Rubin 1991; Greenwald and Rubin 1992). Other components of the Sev pathway have been identified both by looking for mutants with common phenotypes and by screening for enhancers or suppressors of the sev mutant phenotype (Rogge et al. 1991; Simon et al. 1991; Gaul et al. 1992). Here, we have studied the signal transduction pathway regulated by torso, which encodes another Drosophila receptor tyrosine kinase that is required for embryonic development.

The initial specification of cell fate in the Drosophila embryo depends on four separate systems of maternally expressed genes. Three of these systems, anterior, posterior, and terminal, are required for the anteroposterior axis, and another is necessary for the dorsoventral axis (for review, see Nüsslein-Volhard et al. 1987, Stein and Stevens 1991; St. Johnston and Nüsslein-Volhard 1992). Each system includes one or more key gene products whose activity is localized and thereby confers the spatial information required for the differentiation of a specific region of the embryo. The anterior and posterior systems require the localization of the transcripts of the bicoid and nanos genes (Berleth et al. 1988; Wang and 
Lehmann 1991), respectively, and the local production and diffusion of the proteins that they encode provide the necessary spatially restricted activities that regulate downstream gene activities (Driever and Nüsslein-Volhard 1988; Wang and Lehmann 1991). In contrast, in the dorsoventral and terminal systems, no localized product has yet been found. The key genes in these two patternforming systems appear to be transmembrane receptors that are located around the entire circumference of the embryo but are only activated in a specific region, probably by spatially restricted ligands (Stevens et al, 1990; Stein et al. 1991). As yet, the exact mechanism by which these receptors, Toll in the dorsoventral system and Torso in the terminal system, are activated is not understood, although other genes involved in the pathways have been identified (Stein and Stevens 1991; St. Johnston and Nüsslein-Volhard 1992).

The terminal system is responsible for the specification of the nonsegmented termini of the embryo, called the acron and telson (Nüsslein-Volhard et al. 1987; Klingler et al. 1988). The seven maternally active genes of the terminal class are: torso (tor), trunk (trk), $f_{s}(1)$ Nasrat $[(f s(1) N)], f_{s}(1)$ pole hole $\left[\left(f_{s}(1) p h\right)\right]$, torso-like (tsl), 111)pole hole [(111|ph)], and corkscrew (csw) (Perrimon et al. 1985; Klingler et al. 1988; Nishida et al. 1988; Schüpbach and Wieschaus 1989; Degelmann et al. 1990; Stevens et al. 1990; Perkins et al. 1992). Loss-of-function (1-o-f) mutations in any one of these genes in the mother result in deletions of structures from both ends of the embryo. Specifically, in the anterior, the labrum is missing and the head skeleton is collapsed; in the posterior, all structures posterior to abdominal segment 7 are deleted, including abdominal segment 8 , the anal plates, spiracles, filzkörper, and posterior midgut derivatives. Five of the terminal class genes appear to be strict maternal effect genes and are not required at other times in the Drosophila life cycle. The exceptions are $1(1) p h$ and $\operatorname{cs}$, which, in addition to their maternal function in the terminal pathway, are also required during larval stages for imaginal disc growth (Perrimon et al. 1985; Nishida et al. 1988; Perkins et al. 1992).

The three terminal class genes that have been cloned and characterized show significant homologies to other signaling proteins. The tor gene encodes an $\sim 105-\mathrm{kD}$ protein (Tor) containing a possible transmembrane segment and an intracellular domain with several features common to receptor tyrosine kinases (RTKs), with particular similarity to the kinase domain of the plateletderived growth factor (PDGF) receptor (Casanova and Struhl 1989; Sprenger et al. 1989). The tor transcript is detectable throughout the early embryo (Sprenger et al. 1989) and antibodies against Tor show that it is associated with the early embryonic membrane in a uniform distribution around the entire circumference of the embryo (Casanova and Struhl 1989). The 1(1)ph gene encodes the Drosophila Raf- 1 homolog, a serine-threonine kinase (Mark et al. 1987; Nishida et al.1988). It has been reported recently that $c s w$ encodes a non-receptor tyrosine phosphatase that is homologous to the mammalian PTP1C protein (Perkins et al. 1992). The maternally transcribed $1|1| p h$ and $\operatorname{csw}$ transcripts are distributed throughout the mature oocyte and early embryo (Nishida et al. 1988; Ambrosio et al. 1989a; Perkins et al. 1992).

Of the terminal class genes, tor is unique in having gain-of-function (g-o-f) alleles that show a phenotype opposite that shown by the l-o-f alleles. The phenotype of embryos derived from tor g-o-f mutant mothers (hereafter referred to as mutant embryos) is an apparent absence of segmentation in the middle body region and an expansion of terminal structures (Klingler et al. 1988; Schüpbach and Wieschaus 1989). These tor g-o-f alleles have been used to show that four of the other terminal class gene products act upstream of Tor. Double mutants with tor g-o-f mutations and $t r k, t s l, f_{s}(1) N$, or $f_{s}(1) p h$ l-o-f mutations still show the tor g-o-f phenotype, implying that Tor activity is independent of those terminal gene functions (Klingler et al. 1988; Stevens et al. 1990). The exceptions are $l|1| p h$ and $c s w$, which are required for the expression of the tor g-o-f phenotypes and therefore appear to function downstream of Tor (Ambrosio et al. 1989b; Klingler 1989; Perkins et al. 1992). In addition to these maternal genes, two zygotic gap genes, tailless (t1l) and huckebein $\{h k b\}$, are transcribed in domains restricted to the poles of the embryo, and have mutant phenotypes similar to the maternal terminal class genes (Pignoni et al. 1990; Brönner and Jäckle 1991).

It is probable that additional maternal products are required in the signal transduction pathway activated by Tor. Like $1(1) p h$ and $c s w$, these components may not have been identified in previous screens, because they are required at other times in development and are consequently lethal when mutated. In an effort to identify other genes in the terminal pathway, we undertook a large-scale mutagenesis screen for mutations that act as dominant suppressors of the tor g-o-f allele, tor ${ }^{R L 3}$. We chose this recessive allele for such a screen because it is temperature sensitive, suggesting that its phenotype might be suppressible by a partial reduction of the amount of a product required in the pathway. We identified 45 mutations that suppress the tor ${ }^{R L 3}$ phenotype when heterozygous; 17 of these fall into seven complementation groups of more than one member. By complementation tests with mutations identified as enhancers of a hypomorphic allele of $s e v$ [E(sev) loci] (Simon et al. 1991) we show that four of these mutations disrupt the Son of sevenless (Sos) or ras-1 loci. We also show that, in addition to ras-1 and Sos, two other $E$ (sev $)$ mutations suppress the $t^{R L 3}{ }^{R h}$ photype, indicating that the Tor and Sev pathways overlap extensively. Of the new Su(tor) mutations that we isolated, most are lethal mutations, suggesting that they may have other critical roles besides that in the Tor pathway. In addition, several Sultor) loci display maternal or adult mutant phenotypes suggesting that they also act in the epidermal growth factor receptor (EGF-R or Der) pathway at different times in the life cycle. Thus, the suppressor of the tor g-o-f genetic screen that we describe here has proved to be a powerful method to identify genes that participate in a variety of signaling pathways. 


\section{Results}

Temperature sensitivity of tor ${ }^{\mathrm{RL} 3}$

Because products that function downstream of Tor are likely to act in other signaling pathways, mutations in these genes may not be identified in screens for strict maternal effect mutations. For example, if these gene products are involved in cell proliferation and/or differentiation, as $1(1) p h$ and csw are, mutations in them are likely to be lethal during embryonic or larval stages. Therefore, we designed a screen to isolate signal transduction mutations in heterozygous mothers. By looking for mutations that act as dominant suppressors of the tor g-o-f phenotype, it may be possible to identify these mutations in the heterozygous condition. Although most genes are not haploinsufficient when studied in a wildtype background, it is possible to manipulate the conditions to make the function of some genes dosage dependent. In this case, we chose to carry out the screen at: a temperature at which the tor ${ }^{R L 3}$ phenotype might be sensitive to approximately twofold changes in the levels of potential downstream substrates. The heterozygous mutations were not expected to have an effect on the development or viability of the flies or on the fertility of females that are wild type for tor.

The temperature sensitivity of $\operatorname{tor}^{R L 3}$ was advantageous in several ways. First, the $\operatorname{tor}^{R L 3}$ allele is sensitive to genetic background as well as to temperature changes of a few degrees, and it seemed likely that its phenotype would also be sensitive to changes in the amounts of substrates. Second, because homozygous tor ${ }^{R L 3}$ females show $100 \%$ sterility at $27^{\circ} \mathrm{C}$, individual females carrying one copy of a strong suppressor mutation could be detected by even a small fraction of hatching embryos. Third, homozygous $\operatorname{tor}^{R L 3}$ mothers are fertile at $18^{\circ} \mathrm{C}$, so progeny containing a suppressor mutation were recovered by shifting the mother to $18^{\circ} \mathrm{C}$. This feature as well as the viability and fertility of $\operatorname{tor}^{R L 3}$ homozygous males enabled the screen to be done as a maternal effect screen in the Fl generation (see Fig. 2, below). It should be noted that in addition to 1 -o-f mutations in haploinsufficient genes, this type of screen might also detect neomorphic g-o-f and dominant-negative mutations.

Figure 1 shows a comparison of the cuticle phenotype of wild type $(\mathrm{a})$, tor 1 -o-f $(\mathrm{b})$, and g-o-f $\operatorname{tor}^{R L 3}$ mutants at $22^{\circ} \mathrm{C}$ and $27^{\circ} \mathrm{C}$ (c and $\mathrm{d}$, respectively). The tor l-o-f mutant embryo exhibits defects at both the anterior and posterior poles. In contrast, in tor ${ }^{R L 3}$ embryos, terminal structures are present, but there is a disruption of segmentation in the middle region of the embryo (Klingler 1989; Schüpbach and Wieschaus 1989). Although the penetrance of the tor ${ }^{R L 3}$ mutation is $100 \%$ at $27^{\circ} \mathrm{C}$ (i.e., all embryos show some mutant phenotypel, the strength of the phenotype can vary even among embryos from a single female. Of eggs collected from females at $27^{\circ} \mathrm{C}$, $<10 \%$ had one or more ventral denticle belts, $5-10 \%$ had extra rudimentary filzkörper material and/or a duplicated tuft, and $<1 \%$ hatched into first-instar larvae ! Fig. 1d). Virtually all embryos produced some cuticle material, but they were extremely disorganized in comparison with embryos collected at lower temperatures. At $22^{\circ} \mathrm{C}$, a significantly higher percentage of embryos hatched $(40-50 \%)$, and all embryos showed a more organized anteroposterior axis, including at least several denticle belts (Fig. 1c). Thus, $5^{\circ} \mathrm{C}$ changes in the temperature of egg collections show a gradual but reproducible change in the mutant phenotype.

\section{Isolation of suppressors of $\operatorname{tor}^{\mathrm{RL} 3}$ [Su(tor) loci]}

The basic strategy of the screen is shown in Figure 2 and described in more detail in Materials and methods. Fifteen thousand individual females were screened, $\sim 160$ produced embryos with a suppressed phenotype, and progeny were recovered from 130 of these. In the secondary screen, the criteria for suppression were more stringent, both with respect to penetrance and expressivity, and several more lines were eliminated because they failed to show a highly penetrant phenotype. The scheme for the secondary screen and linkage analysis is shown in Figure $2 b$, and the results are summarized in Table 1. Once stocks were established, the Su\{tor $\}$ loci were rescreened more carefully by cuticle preparations, and at this point only 45 individual lines were maintained. The final number of recovered suppressors was 6 mutations on the $\mathrm{X}$ chromosome, 26 mutations on the second chromosome, and 13 mutations on the third chromosome.

\section{Phenotype of suppressed embryos}

Because the suppression screen did not require that embryos survive to adulthood, Su(tor) mutations with a wide range of effects were isolated. Examples of two different classes of Sultor) effects are shown in Figure 3. Females carrying a weak Su(tor) mutation gave rise to no hatching larva, and all the embryos showed a weak but consistently suppressed phenotype (Fig. 3b) when compared with tor ${ }^{R L 3}$ (Fig. 3a). In contrast, strong $S u($ tor $) \mathrm{mu}-$ tations produced embryos with a highly repressed phenotype (Fig. 3c) and 10-20\% hatching larva, although these exhibited weak segmentation defects characteristic of $\operatorname{tor}^{R L 3}$ at $22^{\circ} \mathrm{C}$ and generally did not survive. In addition, the penetrance of some of the $S u(t o r)$ mutations was somewhat variable.

To assess how early the Su(tor) mutations are acting, we examined the expression of $t 11$, which is likely to be one of the first transcriptional targets of the Tor signal transduction pathway. Figure 4 compares the $t 11$ mRNA expression in a wild-type embryo (Fig. 4a), in an unsuppressed tor ${ }^{R L 3}$ embryo at $27^{\circ} \mathrm{C}$ (Fig. $4 \mathrm{~b}$ ), and in a tor ${ }^{R L 3}$ embryo carrying a suppressor (Fig. 4c; Sultor)2-48). In $t_{0 r^{R L 3}}$ mutants, the $t 11$ expression pattern is expanded and variable, particularly in the anterior of the embryo. In the posterior, the $t l l$ expression domain extends anteriorly over one-third to one-half the embryo. In the suppressed embryo, tll expression looks almost wild type, with only a slight expansion of the posterior domain.

\section{Complementation tests}

For complementation tests of dominant Su(tor) loci, sev- 


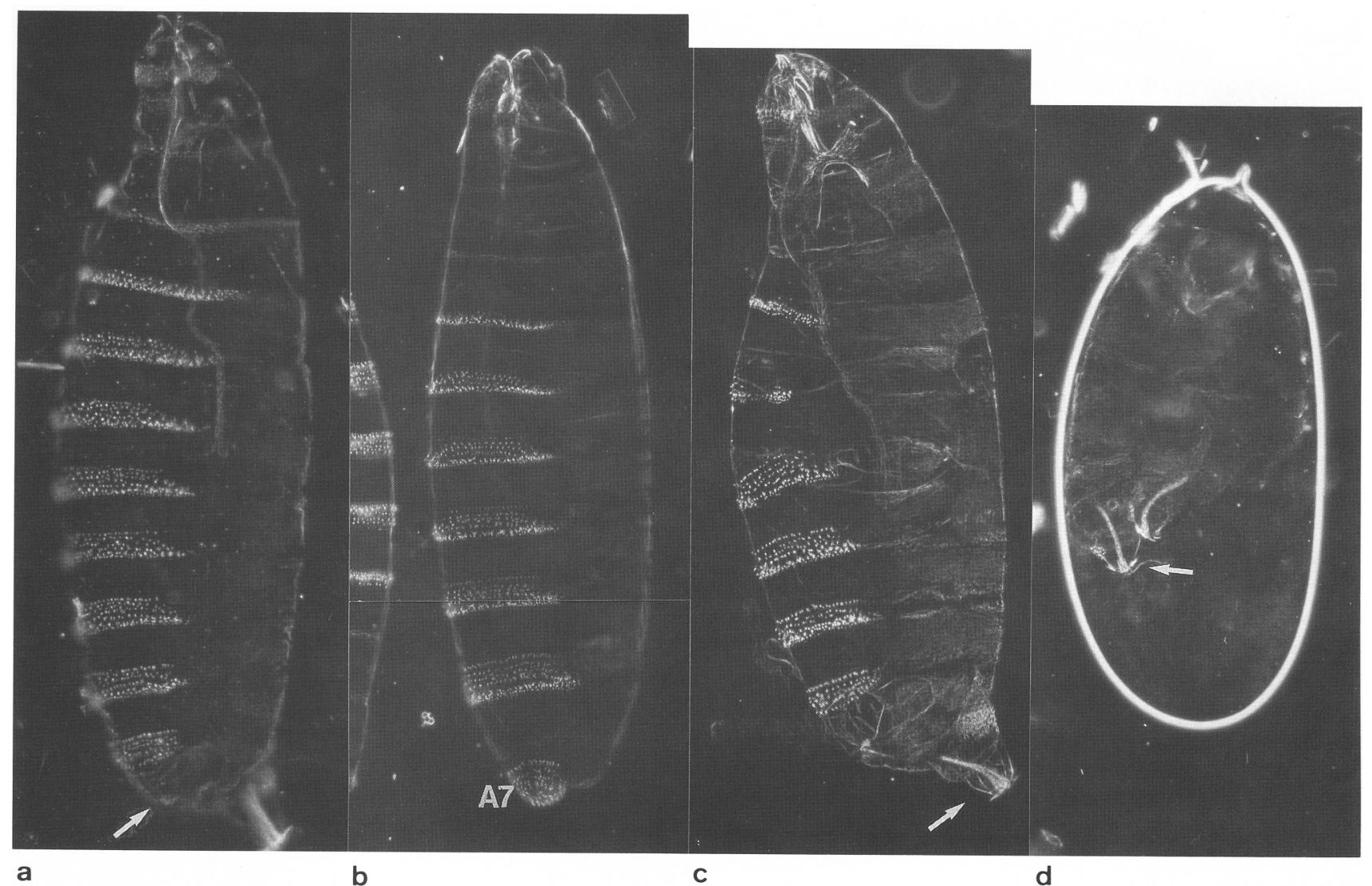

Figure 1. The temperature sensitive g-o-f $t o r^{R L 3}$ allele exhibits a phenotype that is opposite that of a 1-o-f tor allele. Cuticle preparations were done of unhatched larvae to compare the phenotypes of wild-type and various tor mutants to illustrate the temperature sensitivity of $t^{R L 3}$. Embryos are oriented anterior up, ventral to the left; lateral views are shown. In a wild-type embryo $\langle a|$, tor function is required for the development of the terminal regions of the embryo, including the labrum, a part of the head skeleton, and structures posterior to abdominal segment 7 (A7), such as the anal plates and posterior spiracles (arrows). (b) In a tor l-o-f mutant embryo $\left(\right.$ tor $^{P M} /$ tor $\left.^{P M}\right)$, terminal structures are missing: The head skeleton is collapsed, and A7 is seen at the posterior-most point of the embryo. The g-o-f $\operatorname{tor}^{R L 3}$ allele is temperature sensitive and shows defects in the abdominal region of the embryo but not at the termini. (c) At $22^{\circ} \mathrm{C}$, embryos display between five and eight abdominal denticle belts and have normal head and telson structures, including well extended filzkörper (arrow). Segmentation disruptions are primarily seen in the A2 to A5 region. (d) At $27^{\circ} \mathrm{C}$, most abdominal segments are deleted, and embryos differentiate only terminal structures, including spiracles, filzkörper material (arrow), anal plates, and tuft (not visible in this focal plane), and often display disorganized head skeletons.

eral different aspects of their phenotypes were assayed. First, mutations were tested in a straightforward lethal complementation assay. Those flies that did not show a lethal interaction were examined for an obvious adult phenotype. Finally, viable females that carried two separately isolated $S u(t o r)$ mutations were placed into egglaying blocks and their progeny examined for a phenotype resulting from a maternal effect. The results of these assays are described below and summarized in Table 1.

By analogy to $l(1) p h$ and $c s w$, we suspected that the Sultor| mutations would act maternally to suppress tor $r^{R L 3}$ but might also be zygotic lethal. We tested whether we had obtained any lethal complementation groups by crossing balanced suppressor stocks with each other. For the second chromosome crosses, we found three lethal complementation groups, one with three members (2-1) and the others with two each (2-2 and 2-3). Two lethal groups (3-1 and 3-2) with two members each were found on the third chromosome. None of the other crosses showed $100 \%$ lethality.

There were two viable second chromosome Su|tor| mutations [Su|tor|2-68 and Su|tor|2-417] that had slightly rough eyes as homozygotes. When these mutations were crossed with each other, the transheterozygous flies again had rough eyes. This suggests that these two mutations might be affecting other RTK pathways, such as the Sev or DER pathway, that are involved in eye patterning. When one of these mutations, Su|tor|2-417, was crossed with 20 other second chromosome suppressors, no visible adult phenotypes were seen. The specificity of the rough eye phenotype seen with $S u(t o r) 2-417$ and $S u(t o r) 2-68$ transheterozygotes suggests that these mutations are allelic.

The embryos of viable transheterozygous females were examined for a maternal effect. Our expectation was that a homozygous suppressor that was a l-o-f mutation 
a

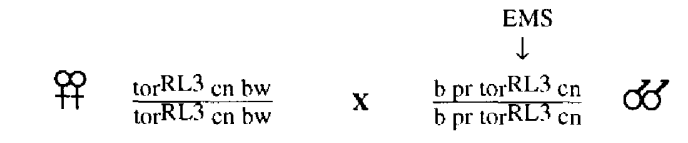

Primary screen: F1

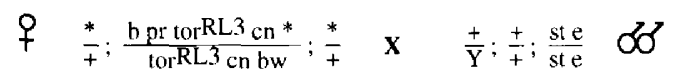

Isolation of individual lines: $\quad F 2$

$$
\begin{aligned}
& \text { ff } \frac{\operatorname{tor} R L 3 \mathrm{cn} \mathrm{bw}}{\mathrm{CyO}} ; \frac{+}{\mathrm{TM} 3} \quad \mathrm{x} \quad \frac{\operatorname{tor}^{\mathrm{RL}} 3 \mathrm{cn}(*)}{+} ; \frac{\left(^{*}\right)}{\mathrm{ste}} ; \frac{\left(^{*}\right)}{\mathrm{Y}} \\
& \text { b Secondary screen and balancing: F3 }
\end{aligned}
$$

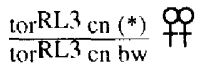

$$
\begin{aligned}
& \text { To retest. }(100 \% \text { have } * \text { ) } \\
& \frac{\operatorname{tor} \mathrm{RL} 3 \mathrm{cn}(*)}{\mathrm{CyO}} 丹 \mathrm{f} \quad \mathrm{X} \quad \text { To make stock. }
\end{aligned}
$$

For the 3rd chromosome:

$$
\begin{aligned}
& \frac{\operatorname{tor}^{\mathrm{RL} 3} \mathrm{cn}}{\mathrm{tor}^{\mathrm{RL} 3} \mathrm{cn} b \mathrm{w}} ; \frac{*}{+} \\
& \frac{\operatorname{tor}^{R L} 3 \mathrm{cn}}{\operatorname{tor} R L 3 \mathrm{cn} \mathrm{bw}} ; \frac{\text { ste }}{+} \text { ff }{ }^{\text {or }} \text { To retcst. (50\% have *) }
\end{aligned}
$$

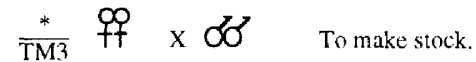

Figure 2. Suppressors of $t o r^{R L 3}$ were isolated in an Fl maternal-effect screen. The basic strategy of the screen for Sultor) mutations as described in Results and in Materials and methods is shown here. In the primary screen $(a)$, mutagenized males were crossed with tor ${ }^{R L 3}$ females and their progeny grown at $18^{\circ} \mathrm{C}$, the permissive temperature for $\operatorname{tor}^{R L 3}$. The homozygous tor ${ }^{R L 3}$ female progeny were crossed with appropriately marked males and placed into individual egg-laying blocks, and their progeny were examined after 2 days at $27^{\circ} \mathrm{C}$. Those F1 females that produced a large percentage of embryos with several abdominal denticle belts were removed and placed in vials at $18^{\circ} \mathrm{C}$. Because meiotic recombination occurs in females, at least five male progeny (F2) were crossed individually to females with balancer chromosomes. In the secondary screen $(b)$, multiple homozygous tor ${ }^{R L 3}$ female progeny from each F2 male were rescreened. If the male carried a suppressor on the second chromosome, which is linked to tor ${ }^{R L 3}$ and $c n, 100 \%$ of his F3 to ${ }^{-R L 3}$ female progeny would carry the suppressor. In these cases, males and females carrying the mutagenized second chromosome (marked with $\mathrm{cn}$ ) over the balancer $\mathrm{CyO}$ were crossed together to make a balanced stock. The suppressors linked to the third chromosome segregated independently of the $t^{R L 3}$ chromosome, so that only $\sim 50 \%$ of the F 3 tor $^{R L 3}$ homozygous females carried it. The mutagenized third chromosome from the F2 male was unmarked but could be distinguished over TM3 from the nonmutagenized chromosome, which was marked with st e. Males and females carrying the putative third chromosome suppressor were crossed together to generate a balanced stock. Because viable X-linked suppressors showed the same segregation pattern as the third chromosome suppressors, they had to be distinguished by further crosses.

should produce embryos resembling tor 1-o-f mutants. None of the viable trans-heterozygous female combinations produced embryos with this phenotype. Because most of these were scored in the presence of $t o r^{R L 3}$, they showed variable degrees of suppression at $27^{\circ} \mathrm{C}$, and a high percentage of hatching embryos at $18^{\circ} \mathrm{C}$, as expected. However, in a few cases, trans-heterozygous females produced embryos that did not hatch and, on closer examination, were seen to have chorion defects. These defects probably result from a disruption of the DER pathway required for follicle cell and embryonic patterning (see below and Fig. 6). This maternal phenotype was not highly penetrant and was seen primarily with several combinations of second chromosomelinked Su(tor) mutations, as indicated in Table 1.

Four viable X-linked Su(tor) mutations were female sterile as homozygotes and produced eggs that were discolored and collapsed. When these mutations were crossed together, the same female sterile phenotype was obtained. These mutations are allelic and appear to define a viable female sterile complementation group, indicated as Sultor)1-1 in Table 1.

It should be noted that it is possible that mutations complement each other in the above assays but actually disrupt the same locus, as they were not isolated because they showed a phenotype on their own. That is, we do not know what phenotype a homozygous mutant will show. Such complementation can be resolved by mapping or possibly by the isolation of more alleles. Conversely, we have also detected nonallelic lethality between Su|tor|2-85 and Su|tor|2-93, which map to different arms of the second chromosome. Both of these are unhealthy stocks and show partial dominant female sterility, suggesting that they are not straightforward l-o-f mutations.

\section{Maternal vs. zygotic requirement}

Because the gap segmentation genes are among the earliest genes transcribed from the zygotic genome, we predicted that the components of the Tor signal transduction pathway required for $t l l$ and $h k b$ expression would be provided maternally. We therefore classified further the Sultor) mutations by testing whether they function maternally or zygotically. This was done by crossing males that were heterozygous for the suppressors to homozygous tor $^{R L 3}$ females and scoring the cuticle phenotype of the progeny. Half of the progeny should inherit the suppressor from their father. If the suppressor is required maternally, the genotype of the father has no influence, and so no suppression should be seen. Table 1 shows the classification into maternally and zygotically active groups. There are 38 maternally active and $7 \mathrm{zy}-$ gotically active $S u(t o r)$ mutations. In addition, there are a few cases in which a Su(tor) mutation seems to be active both maternally and zygotically. It is possible that a mutation could be a zygotic suppressor, even if its wild-type product is normally needed maternally, for example, by acting as a dominant-negative mutation that interfers with the wild-type, maternally provided product.

\section{Mapping of $\mathrm{Su}($ tor) mutations}

The maternal-effect suppressors that showed the most 
Table 1. Summary of Su|tor| mutations

\begin{tabular}{|c|c|c|c|c|c|c|}
\hline Stock name ${ }^{a}$ & $\mathrm{v}$ or $\mathrm{l}^{\mathrm{b}}$ & $\mathrm{m}$ or $\mathrm{z}^{\mathrm{c}}$ & Group $^{d}$ & Position ${ }^{e}$ & $\mathrm{Elp}^{\mathrm{f}}$ & Comments \\
\hline \multicolumn{7}{|c|}{ First chromosome } \\
\hline $1-19$ & $\mathrm{v}(\mathrm{FS})$ & $\mathrm{m}$ & $1-1$ & $\mathrm{cv}$ and $\mathrm{c}$ & weak & homozygous females \\
\hline $1-134$ & $\mathrm{v}(\mathrm{FS})$ & $\mathrm{m}$ & $1-1$ & $\mathrm{cv}$ and $\mathrm{c}$ & weak & produce collapsed \\
\hline $1-285$ & $\mathrm{v}(\mathrm{FS})$ & $\mathrm{m}$ & $1-1$ & $\mathrm{cv}$ and $\mathrm{c}$ & & eggs \\
\hline $1-352$ & $\mathrm{v}(\mathrm{FS})$ & $\mathrm{m}$ & $1-1$ & $\mathrm{cv}$ and $\mathrm{c}$ & & \\
\hline $1-106$ & $\mathbf{v}$ & $\mathrm{m}$ & & & & \\
\hline $1-163$ & $\mathrm{v}$ & $\mathrm{m}$ & & & no & \\
\hline \multicolumn{7}{|c|}{ Second chromosome } \\
\hline $2-15$ & 1 & $z$ & & & & \\
\hline $2-17$ & 1 & $\mathrm{~m}$ & $2-1$ & $\sim 2-16$ & no & \\
\hline $2-28$ & 1 & $\mathrm{~m}$ & & $\sim 2-60$ & no & \\
\hline $2-48$ & 1 & $\mathrm{~m}$ & & near $\mathrm{cn}$ & no & \\
\hline $2-56$ & $\mathrm{v}$ & $\mathrm{m}$ & & & & \\
\hline $2-60$ & 1 & $\mathrm{~m}$ & $2-1$ & $-2-16$ & no & \\
\hline $2-68$ & $\mathbf{v}$ & $\mathrm{m}$ & $2-4$ & & & rough eyes \\
\hline $2-83$ & 1 & $\mathrm{~m}$ & $2-3$ & $\sim 2-60$ & yes* & chorion interactions \\
\hline $2-85$ & 1 & $\mathrm{~m}$ & $2-1$ & $\sim 2-16$ & no & semidominant FS \\
\hline $2-87$ & $\mathrm{v}$ & $\mathrm{m}$ & & & & \\
\hline $2-93$ & 1 & $\mathbf{m}$ & & $\sim 2-76$ & yes* & chorion interactions \\
\hline $2-113$ & $\mathrm{v}$ & $\mathrm{m}$ & & & & \\
\hline $2-157$ & 1 & $\mathrm{~m}$ & $2-2$ Sos & $34 \mathrm{D}$ & yes* & \\
\hline $2-180$ & 1 & $\mathrm{~m}$ & & $c$ and bw & yes* & semidominant FS \\
\hline $2-187-1$ & 1 & $\mathrm{~m}$ & & & no & \\
\hline $2-187-3$ & $\mathbf{v}$ & $\mathrm{m}$ & & & & \\
\hline $2-191$ & $\mathrm{v}$ & $\mathrm{m}$ & & & & \\
\hline $2-237$ & 1 & $\mathrm{~m},|z|$ & & $\sim 2-95$ & yes & \\
\hline $2-278$ & 1 & $\mathrm{~m}, \mathrm{z}$ & & & weak & \\
\hline $2-280$ & $\mathbf{v}$ & $\mathrm{m}$ & & & & \\
\hline $2-321$ & 1 & $\mathrm{~m}$ & & & weak & \\
\hline $2-341$ & 1 & $\mathrm{~m}$ & & & & \\
\hline $2-361$ & 1 & $\mathrm{~m}$ & $2-3$ & $\sim 2-60$ & weak & \\
\hline $2-399$ & $\mathbf{v}$ & $z$ & & & & \\
\hline $2-405$ & 1 & $\mathrm{~m}$ & $2-2 \operatorname{Sos}$ & $34 \mathrm{D}$ & yes & \\
\hline $2-408$ & 1 & $\mathrm{~m}$ & & & weak & \\
\hline $2-417$ & $\mathbf{v}$ & $\mathrm{m}$ & $2-4$ & & yes & rough eyes \\
\hline \multicolumn{7}{|c|}{ Third chromosome } \\
\hline $3-8$ & 1 & $\mathrm{~m}, \mathrm{z}$ & & & & \\
\hline $3-38$ & 1 & $\mathrm{~m}$ & $3-1$ & $\sim 3-48$ & weak* & \\
\hline $3-42$ & 1 & $\mathrm{~m}$ & $3-1$ & $\sim 3-48$ & & \\
\hline $3-91$ & 1 & $z$ & & & & \\
\hline $3-168$ & $\mathrm{v}$ & $z$ & & & & \\
\hline $3-293$ & 1 & $z$ & & & & \\
\hline $3-307$ & 1 & $\mathrm{~m}$ & & & & \\
\hline $3-333$ & $\mathrm{v}$ & $z$ & & & & \\
\hline $3-337$ & 1 & z & & & & \\
\hline $3-341$ & 1 & $\mathrm{~m},(\mathrm{z})$ & $3-2$ ras -1 & $85 \mathrm{D}$ & weak & \\
\hline $3-344$ & $\mathrm{v}$ & $\mathrm{m}$ & & & & \\
\hline $3-404$ & 1 & $\mathrm{~m}, z$ & $3-2$ ras -1 & $85 \mathrm{D}$ & yes & \\
\hline
\end{tabular}

The $S u(t o r)$ mutations define seven complementation groups and exhibit a variety of phenotypes. Many of the characteristics of the $\mathrm{Su}$ (tor) mutations that were assayed as described in Results and Materials and methods are summarized here.

${ }^{a}$ Chromosomal linkage and stock numbers.

${ }^{\mathrm{b}}$ The viability ( $\mathrm{v}$ ) or lethality (l) of the Su(tor) chromosome as a homozygote is indicated. (FS) Female sterility. [Note that in most cases the $\mathrm{Su}$ (tor) mutation has not been recombined off the mutagenized chromosome, so the observed lethality may be caused by a second mutation on the chromosome.]

${ }^{\mathrm{c}}$ Maternal $(\mathrm{m})$ or zygotic $(\mathrm{z})$ action of the suppressor.

dComplementation group and identity.

eMap positions.

${ }^{\text {i }}$ Su(tor) stocks that were tested for suppression of Elp and the results of those assays [those with an asterisk were scored using SEM [see Fig. 6)]. 


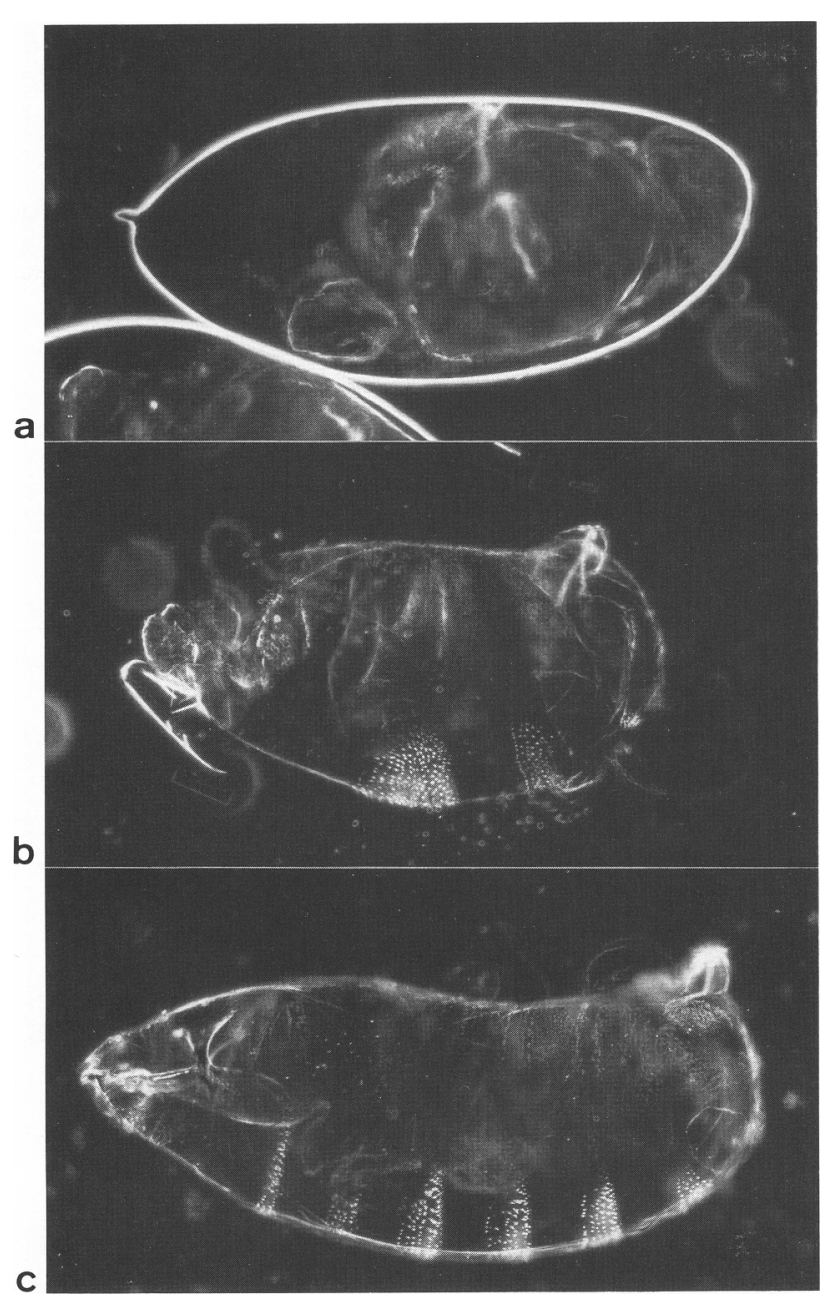

Figure 3. The Sultor| mutations show a range of suppression strengths. Cuticle preparations were done on late-staged tor $^{R i .3}$ embryos from mothers containing a Su(tor) mutation collected at $27^{\circ} \mathrm{C}$. All embryos are oriented with anterior to the left, ventral down, and lateral views are shown. An unsuppressed $t^{R L 3}$ embryo is shown $(a)$ compared with a tor ${ }^{R L 3}$ embryo containing a weak suppressor $[(b) \mathrm{Su}($ tor $] 2-15]$ and a strong suppressor $[(c)$ Su|tor|2-48]. The weak suppressors never give rise to hatching embryos, but all show at least two denticle belts, whereas the strong suppressors often produce $10-20 \%$ hatching embryos.

consistent suppression were chosen for reccmbination mapping. There were several problems to consider. First, it was necessary to prove that the second chromosome suppressors were not partial revertants of tor $^{R L 3}$ and that they could be separated from tor ${ }^{R L 3}$. Second, although most of the suppressors were on lethal chromosomes, this did not necessarily imply that the suppressor itself was lethal, as there might be more than one mutation induced on the chromosome. Therefore, we first had to map the mutations as suppressors in a homozygous tor $^{R L 3}$ background. For this purpose, the mutations linked to the second chromosome were mapped relative to $c n$ (which is closely linked to tor) using dominant visible markers (see Materials and methods). These preliminary recombinations allowed us to derive a rough map position and to choose recessive visible markers for further mapping. In some cases we were also able to test whether recombinant chromosomes still carried both the suppressor and a lethal mutation. More detailed recombination mapping was done for a few of the Sultor) loci (see Materials and methods). The results of the mapping are shown in Table 1.

\section{Complementation with $\mathrm{E}(\mathrm{sev})$ mutations}

One of the lethal complementation groups, Su\{tor|2-2,

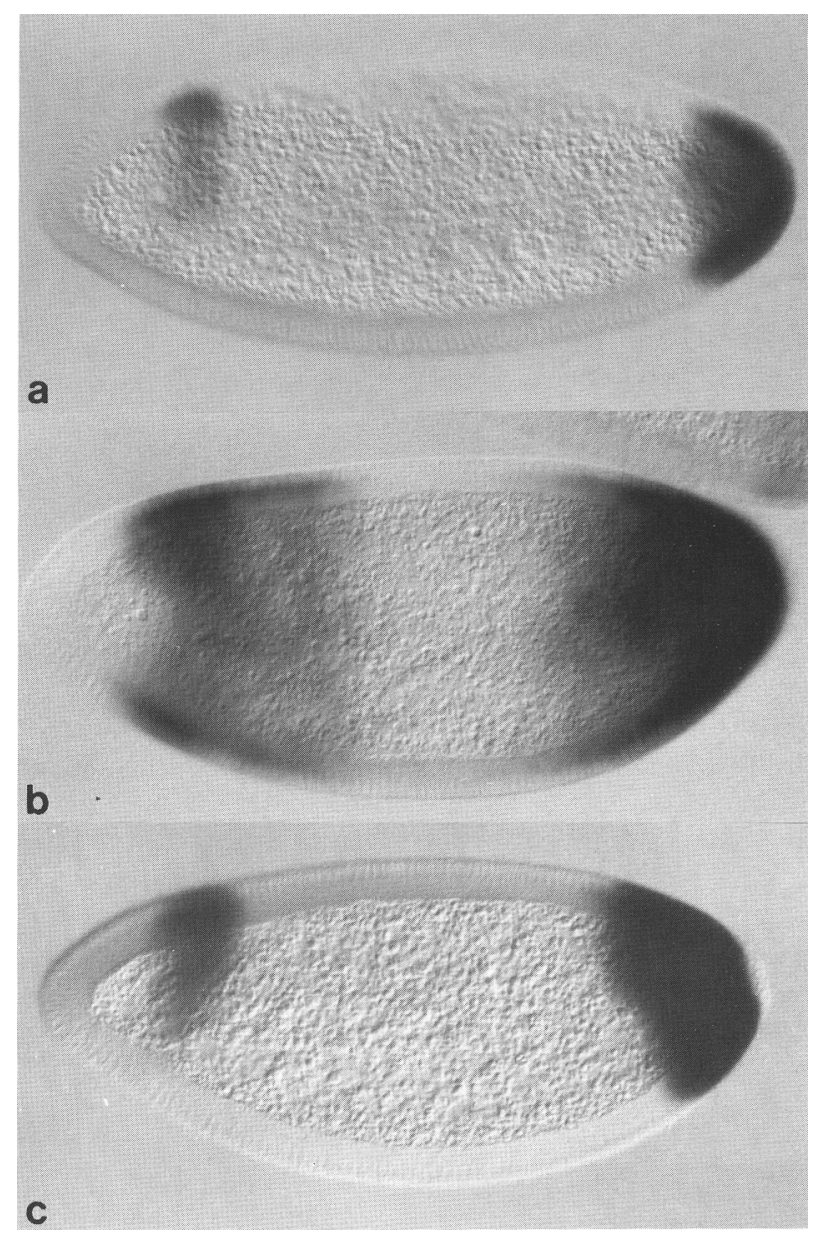

Figure 4. Expression of the gap gene $t l l$ is restored to wild type in suppressed tor ${ }^{R L 3}$ embryos. The expression of $t 11$ transcripts was detected by in situ hybridization in whole-mount embryos using a digoxygenin-labeled $t 11$ cDNA probe. Embryos were collected at $27^{\circ} \mathrm{C}$ from mothers that were wild type $(a)$, homozygous $\operatorname{tor}^{R L 3}|b|$, or homozygous tor ${ }^{R L 3}$ containing one Sultor mutation $[(c)$ in this example, Su(tor)2-48]. Embryos are oriented anterior to the left and dorsal up; all are at the cellular blastoderm stage. In comparison with wild type $\{a\}, \operatorname{tor}^{R L 3}$ embryos show varying degrees of $t l l$ expression that expands toward the middle of the embryo $|b|$, which results in the disruption of the segmentation pattern in this region, as seen in Fig. $1, c$ and $d$. With one copy of a suppressor mutation, $S u(t o r) 2-48, t l l$ expression in tor $^{R L 3}$ embryos is restricted to its normal anterior and posterior pattern, with only a slight broadening of these domains $(c)$. 
mapped very close to Sos (Rogge et al. 1991; Simon et al. 1991). We obtained l-o-f lethal Sos alleles and found that our two Sultor|2-2 mutations failed to complement them, whereas 10 other second chromosome-linked Su(tor) loci did complement Sos. It has been shown that Sos encodes a protein with putative homology to the Saccharomyces cerevisiae cdc 25 gene product, a guanine nucleotide exchange factor that is proposed to be involved in the Ras pathway. This suggested that substrates in the Sev pathway may also be used in the Tor pathway. We therefore carried out complementation tests with the other $E(\mathrm{sev})$ mutations. From these tests we found that the lethal pair, Sultor|3-341 and Su|tor|3404 , failed to complement the lethality of $E(\operatorname{sev}) 3 C^{\text {eib }}$ and $E\left(s e v \mid 3 C^{e 2 f}\right.$, which are mutations in the ras-1 gene. Thus, both ras-1 and Sos function in both the Tor and Sev pathways, indicating that the screen was successful in isolating mutations in known signaling genes. The phenotype of tor $^{R L 3}$ embryos carrying the ras-1 and Sos mutations is shown in Figure 5, a and b, respectively. The other crosses between $E(\mathrm{sev})$ and $S u($ tor $)$ mutations were viable and did not show a visible adult phenotype, and trans-heterozygous females showed no maternal effect on the chorion structure or embryonic pattern formation.

From the results described above, it appears that RTKactivated pathways share at least some substrates. We therefore tested the other $E\{s e v \mid$ mutations for an ability to suppress $t^{2} r^{R L 3}$. The $E(\mathrm{sev})$ mutations were isolated in a screen for enhancers of a hypomorphic sev allele, that is, for mutations that reduce sev activity (Simon et al. 1991). By testing for their ability to suppress the g-o-f tor ${ }^{R L 3}$ allele, we are also looking for a reduction of Tor activity. The $E(\operatorname{sev}) 2 B$ mutation, represented by a single allele, was recombined onto a tor ${ }^{R L 3}$ chromosome and backcrossed to $\operatorname{tor}^{R L 3}$. Females homozygous for $\operatorname{tor}^{R L 3}$ and heterozygous for $E(\mathrm{sev}) 2 B$ produced suppressed embryos when compared with control embryos lacking the $E(\mathrm{sev}) 2 B$ mutation (Fig. $5 \mathrm{c}$ ). The $E(\mathrm{sev}) 2 B$ mutation appears to be a weak suppressor compared with ras-1 and Sos mutations (Fig.5, cf. c with a and b).

The other three $E(\mathrm{sev})$ loci linked to the third chromosome were crossed into a homozygous $t^{R}{ }^{R L 3}$ stock, and embryos were scored for suppression. The two $E\langle\operatorname{sev}\rangle 3 A$ alleles showed weak suppression, whereas $E(\operatorname{sev}) 3 B$ and $E(s e v) 3 D$ did not show convincing suppression over several days of analysis. The two $E(\mathrm{sev}) 1 \mathrm{~A}$ alleles on the $\mathrm{X}$ chromosome show very strong, highly penetrant suppression of $t^{R L 3}$ (Fig. 5d). On the basis of their map position and failure to complement, these $E(\mathrm{sev}) 1 \mathrm{~A} \mathrm{mu}$ tations are likely to be alleles of $\operatorname{csw}$ (Simon et al. 1991; Perkins et al. 1992). These same $E$ (sev) mutations have been shown to suppress Elp, a dominant allele of the EGF-R (Der), indicating that the Sev, Der, and Tor RTK pathways contain common signaling components.

\section{Interactions in the Drosophila EGF-R (Der) pathway}

As mentioned previously, weak interactions between some $S u(t o r)$ loci suggested a disruption of the Der sig-

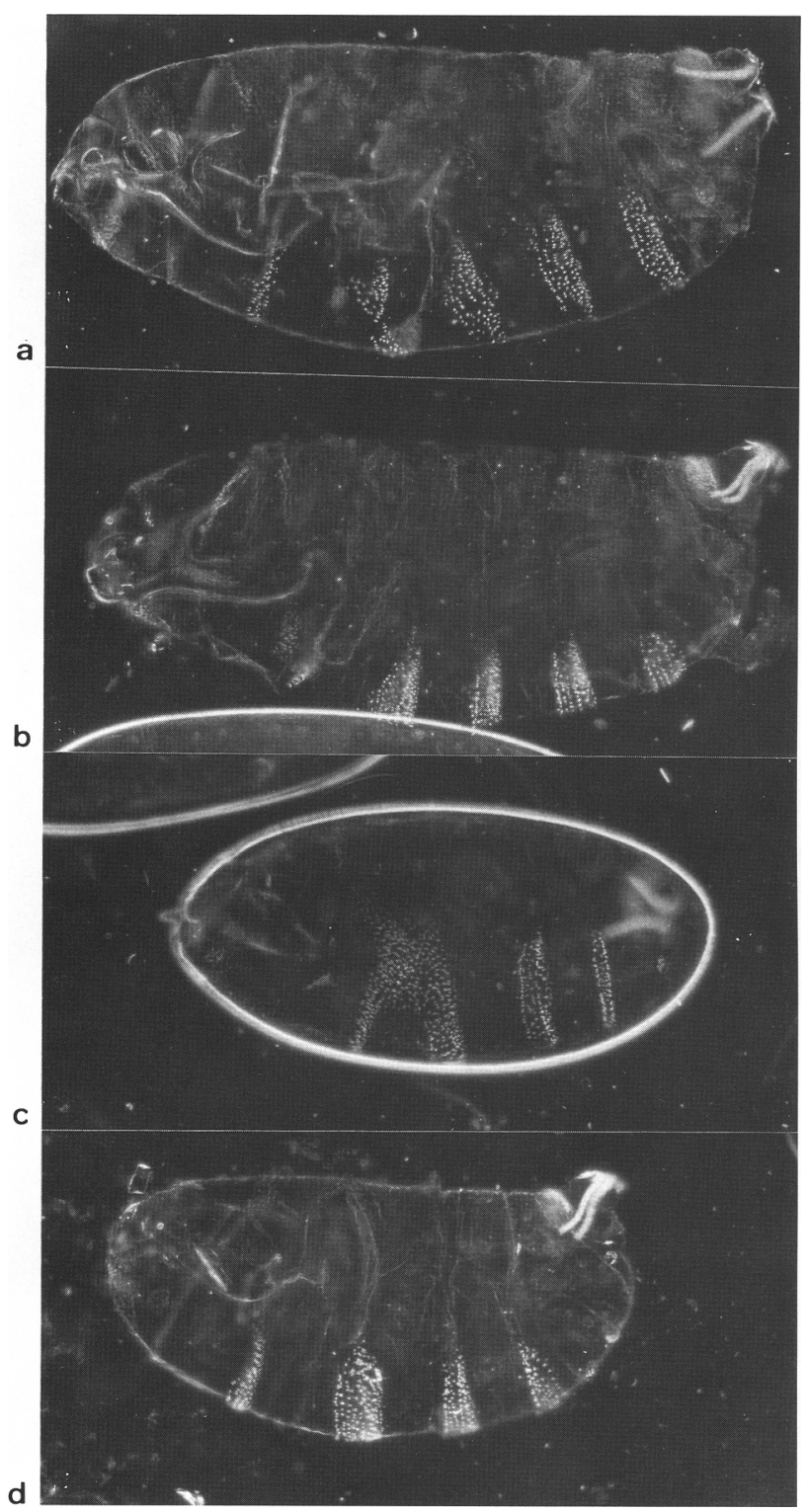

Figure 5. Several $E(\mathrm{sev})$ mutations including ras-1 and Sos also act as suppressors of $\operatorname{tor}^{R L 3}$. Cuticle preparations were done on late-staged $t o r^{R L 3}$ embryos containing a $S u(t o r)$ or $E(\mathrm{sev})$ mutation, at $27^{\circ} \mathrm{C}$. All embryos are oriented with anterior to the left, ventral down, and lateral views are shown. Two of the lethal Su(tor) complementation groups were found to be allelic to mutations in ras-1 and Sos. Both ras-1 $|a|$ and Sos $|b|$ act as strong, highly penetrant suppressors, giving rise to embryos with four to six abdominal denticle belts, as seen in $\operatorname{tor}^{R L 3}$ embryos at $22^{\circ} \mathrm{C}$ (cf. Fig. 1c). Both also show normal termini. (c) $E$ (sev) $2 B$ or crk-like, a putative $\mathrm{SH} 2$-containing adaptor molecule, is a fairly weak suppressor. These embryos generally are more disorganized than those shown in $a$ and $b$ and cannot be easily removed from their vitelline membrane. (d) $E(\mathrm{sev}) 1 \mathrm{~A}$ appears to correspond to a $\operatorname{csw}$ mutation and also acts as a suppressor of tor ${ }^{R L 3}$. These suppressed embryos are intermediate in phenotype and are usually weaker than ras-1 $\{a \mid$ or Sos $(b)$ but stronger than $E[\operatorname{sev}|2 B| c \mid$.

naling pathway that is required in the follicular epithelium to establish the dorsoventral polarity of the egg. As 
transheterozygotes, several Su(tor) mutations show partial female sterility and produce embryos with obvious chorion defects, two examples of which are shown in Figure $6, b$ and $c$. These phenotypes can be interpreted as a partial ventralization of the chorion pattern. A similar phenotype is produced by several other maternal-effect mutations, including the torpedo (top) alleles of Der (Schüpbach and Wieschaus 1989). The Su(tor) combinations in which this phenotype is seen are indicated in Table 1.

We also tested several of the Su(tor) mutations for their ability to suppress the Elp rough eye phenotype. Elp appears to encode a hyperactive Der protein, resulting in disorganized ommatidia and a rough eye (Baker and $\mathrm{Ru}-$ bin 1989|. Adult flies that were heterozygous for Elp and for a single $S u(t o r)$ mutation were scored for a suppression of the rough eye, and several samples were chosen for scanning electron microscopy (SEM). An example of a wild-type eye, an Elp eye, and a $S u(t o r), E l p$ eye are shown in Figure 7, a-c. The Su(tor) mutations that were tested in this assay are indicated in Table 1.

\section{Discussion}

We have used a temperature-sensitive g-o-f allele of the maternal terminal-class gene tor to identify components of the signal transduction pathway that is activated by the receptor tyrosine kinase Tor. In a large-scale screen for suppressors of the tor g-o-f phenotype, we isolated mutations in five lethal and two viable complementation groups, as well as $>20$ apparently "single hit" mutations. The $S u(t o r)$ mutations are dominant because females carrying one copy of a given mutation show suppression of the tor ${ }^{R L 3}$ homozygous phenotype. Suppression can be characterized by a restoration of abdominal segments and a generally more organized cuticle and also by a correlative normalization of the $t l l$ expression pattern. These Su(tor) mutations could be acting in several ways, for example, as 1-o-f mutations that reduce the amount of a product in the pathway (i.e., a dosage effect), as dominant negatives, or as overactive negative regulators of the pathway. On the basis of the low allele frequency and interactions between apparently nonallelic loci, it is likely that many of the Su(tor) mutations are not simple l-o-f alleles. They could, for example, be g-o-f mutations that act as hypermorphs or dominant negatives. While this type of dominant screen is clearly productive, not all signaling genes can be identified in this way. For example, we assayed previously isolated 1-o-f alleles of $1 / 1) \mathrm{ph}$ and $t I l$, and neither was able to suppress $\operatorname{tor}^{R L 3}$ under the conditions of our screen (Klingler 1989; data not shown|. Previous reports, however, suggested that $1|1| p h$ and tll mutations showed a dosage effect on the viability of $\operatorname{tor}^{R L 3}$ embryos (Ambrosio et al. 1989b; Strecker et al. 1989/. The difference between these results may be explained by the different assay conditions, such as temperature and genetic background.

\section{Homology with other signaling proteins}

Screens for suppressors or enhancers of the RTK, Sev,

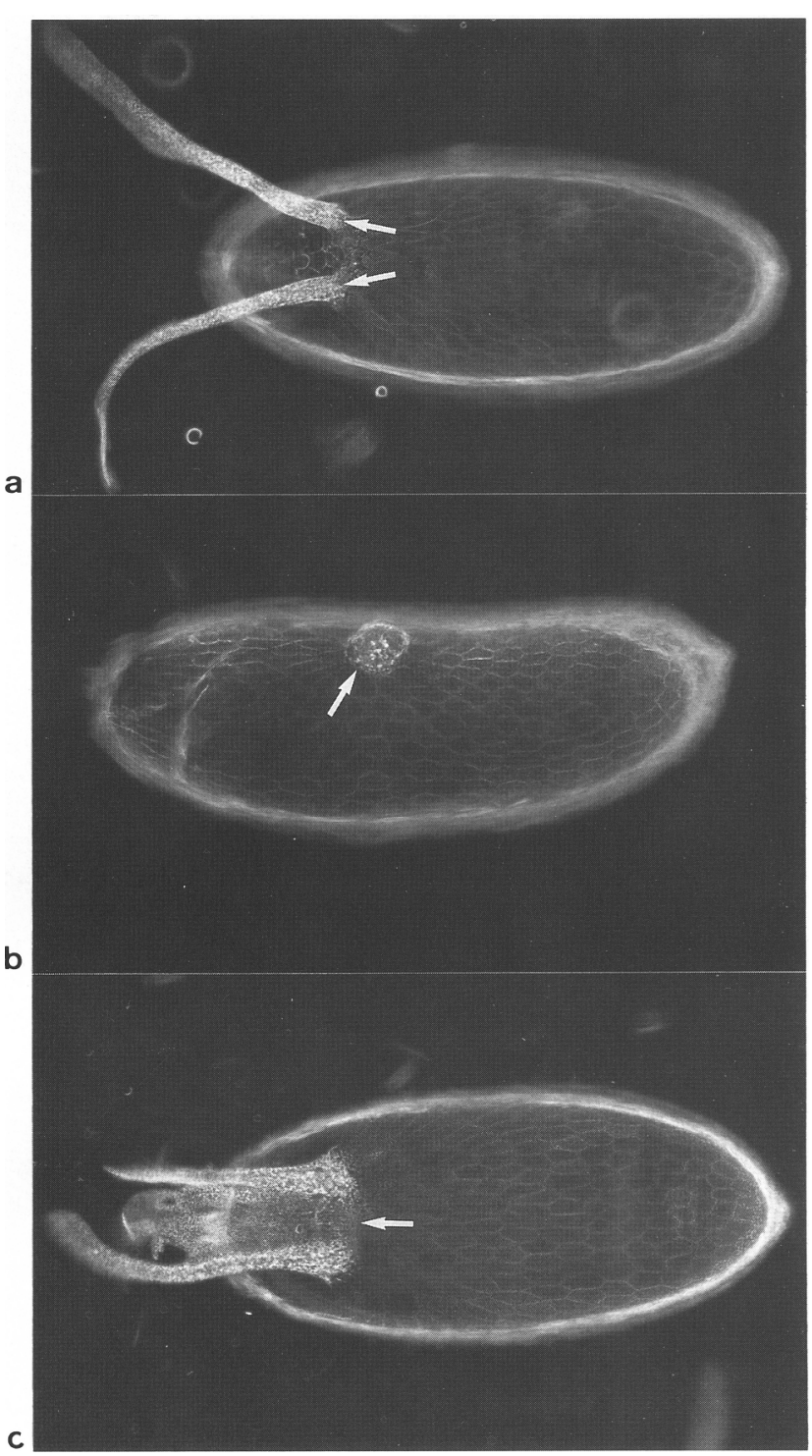

Figure 6. Several Su(tor) mutations function maternally to determine pattern in the follicle cells. The effect of the $S u(t o r)$ mutations on the follicle cell pattern was seen by examining the chorions of embryos from mothers carrying combinations of Su(tor) mutations. These phenotypes are likely to be the result of a disruption of Der dorsoventral patterning pathway. Embryos are oriented with anterior to the left; $a$ and $c$ are dorsal views, and $b$ is a slightly more lateral view. $(a)$ Sultor|2-28/ Sultor)2-83 transheterozygous females do not show an interaction and give rise to embryos with approximately normal chorions, with the dorsal appendages appropriately spaced and positioned (arrows). In contrast, the Su(tor)2-93 mutation interacts with several other mutations: (b) Su(tor)2-93/Su(tor)2-83 females produce some embryos that display a strongly ventralized phenotype like that seen with the top alleles of Der. The dorsal appendages are greatly reduced and are displaced toward the posterior pole (arrow). (c) Sultor)2-93/Su(tor)2-405 (Sos) females also give rise at a lower frequency to embryos with a weaker chorion phenotype. The dorsal appendages of this embryo are broader at their base (arrow) and are perhaps duplicated but are shorter in length as compared with $a$. 


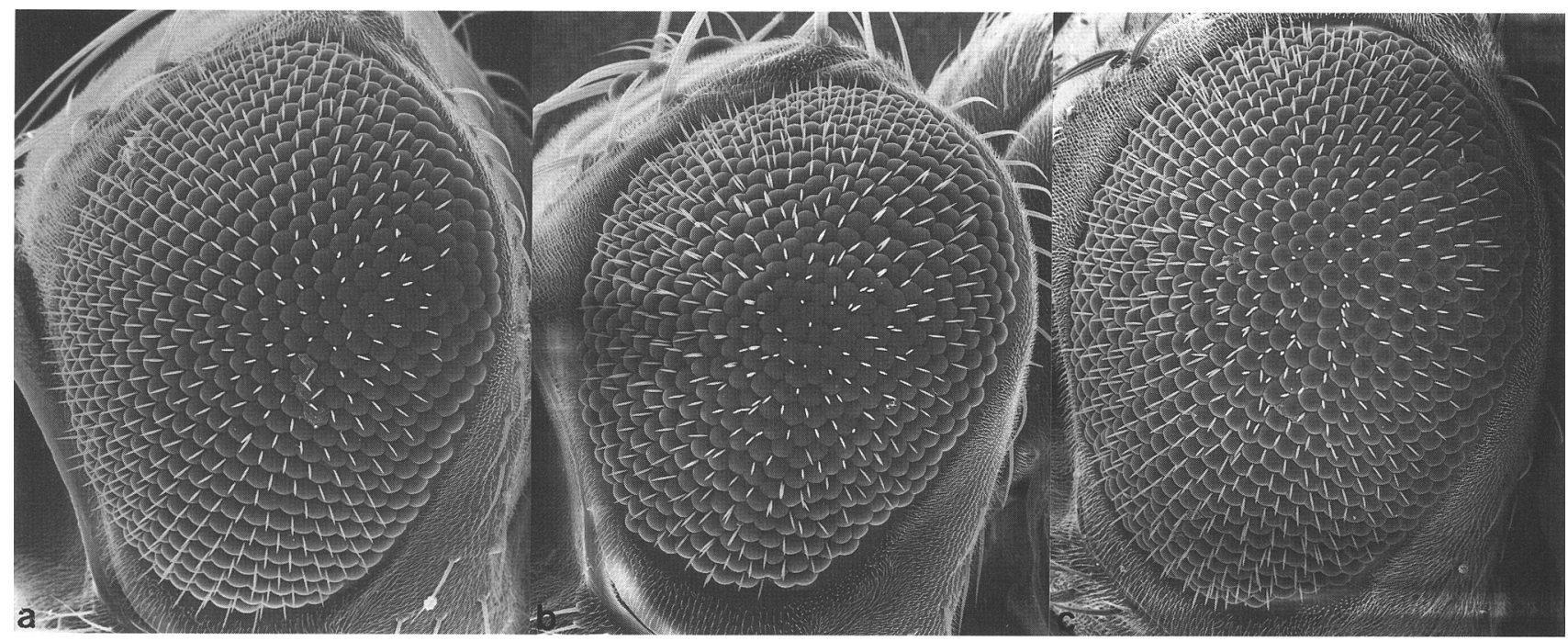

Figure 7. The $S u(t o r)$ mutations can function in the Der pathway to suppress the Elp phenotype. Several Su(tor) mutations were crossed with Elp, a dominant hyperactive allele of Der that results in a rough eye phenotype, and eyes of transheterozygous Elp/Sultor) flies were examined under a low-power microscope. Approximately half of the crosses showed a consistent suppression of Elp, as indicated in Table 1. Several samples were examined in more detail using SEM. Eyes are oriented anterior to the left, and dorsal up. (a) The wild-type eye shows a regular array of hexagonal ommatidia with alternately spaced hairs. $(b)$ The Elp eye is smaller and rougher around the perimeter. The ommatidia are not arranged properly, and the hairs emerge in an irregular pattern. $(c)$ An Elp/ Sultor|2-93 eye displays a more organized array of ommatidia compared with $b$, and most of the hairs are also regularly spaced. Magnification, $200 \times$ for $a$ and $c ; 220 \times$ for $b$.

have led to the identification of Drosophila homologs of several genes known to be involved in signal transduction in species as diverse as yeast, C. elegans, and humans (Hariharan et al. 1991; Rogge et al. 1991; Simon et al. 1991; Bonfini et al. 1992; Gaul et al. 1992). We found that several of our $\mathrm{Su}$ (tor) loci corresponded to mutations in two previously cloned $E(\mathrm{sev})$ loci: ras-1, which encodes a GTPase (Neuman-Silberberg et al. 1984; Brock 1987; Simon et al. 1991), and Sos, which encodes a guanine nucleotide exchange factor thought to act in the Ras pathway (Simon et al. 1991; Bonfini et al. 1992). By directly testing other $E(\mathrm{sev})$ loci, we found that three more of these mutations suppressed the $\operatorname{tor}^{R L 3}$ phenotype: $E(\mathrm{sev}) 1 A, E(\mathrm{sev}) 2 B$, and $E(\mathrm{sev}) 3 A$ (Simon et al. 1991). It has been reported that $E(\operatorname{sev}) 2 B$ (also called crk-like) encodes a protein (Crk-le) containing $\mathrm{SH} 2$ and $\mathrm{SH} 3$ domains (Simon et al. 1993 and pers. comm.), similar to the C. elegans protein encoded by the sem-5 gene (Clark et al. 1992) and the vertebrate proteins, v-Crk (Mayer et al. 1988) and GRB2 (Lowenstein et al. 1992) which also consist mainly of SH2 and $\mathrm{SH} 3$ domains. It is thought that SH2 domains mediate protein-protein interactions by binding to phosphotyrosine residues (Margolis 1992), and thus that proteins of this last group may serve as adaptors between catalytically active signaling proteins. In particular, GRB2 was isolated by its ability to bind to a phosphotyrosine residue of the activated EGF-R and is proposed to link the receptor with Ras (Lowenstein et al. 1992). It is not certain, however, that GRB2 binds directly to the EGF-R in vivo, so no conclusions can be made about the epistatic relationships between this and other downstream genes. Thus, in addition to the Sultor) loci not yet characterized, this dominant suppressor screen added three known components to the Tor pathway.

To date, then, five known signaling molecules are required downstream of Tor: Raf-1, a serine-threonine kinase (Nishida et al. 1988; Ambrosio et al. 1989a); Csw, a tyrosine phosphatase (Perkins et al. 1992); Ras-1, a GTPase; Sos, a nucleotide exchange factor; and Crk-le, an SH2-SH3 domain protein (Simon et al. 1993). All of these gene products have been shown to act in other Drosophila RTK pathways (Rogge et al. 1991; Simon et al. 1991) and are thus involved in cell fate determinations at other times during the life cycle. It is interesting that these proteins, with the exception of Raf-1, show a strong dosage effect under certain conditions, suggesting that the on/off state of these pathways is in a sensitive equilibrium. In vertebrates, many of these signaling molecules can be mutated such that their apparently unregulated activity can lead to cellular transformation (Cantley et al. 1991). In Drosophila, hyperactivity of RTKs does not generally seem to promote tumor growth but, instead, alters the terminal differentiation pattern of specific groups of cells (Klingler et al. 1988; Baker and Rubin 1989; Strecker et al. 1989; Basler et al. 1991; Fortini et al. 1992). One implication of these observations is that the primary role of Drosophila RTKs is in critical decisions of cell fate determination, not in the regulation of the cell cycle or in the maintenance of cell viability, although Der may be an exception to this on the basis of its embryonic lethal phenotype (Prince et al. 1989; Schejter and Shilo 1989). However, as we understand more about signal transduction in Drosophila, we will no 
doubt be able to assign more roles to RTKs and their downstream effectors.

\section{Overlap in the pathways}

Several of the downstream effectors of Tor, Sev, and Der described above appear to be generally expressed and to act in multiple pathways. The sophisticated genetics of Drosophila has allowed us to identify these signaling molecules by focusing on a particular in vivo function while not disrupting others. Because of this extensive overlap, it may be difficult to understand the various mutant phenotypes and to dissect the functional relationships between signaling molecules. Because most of the Su(tor) mutations are autosomally linked and lethal, their maternal-effect phenotype cannot be looked at directly by inducing germ line clones by mitotic recombination. Another way to test for a maternal-effect, germline-dependent phenotype is to transplant potentially mutant pole cells into a sterile $o v o^{D}$ host (Lehmann and Nüsslein-Volhard 1986). However, it is likely that some of these signaling genes may be required earlier in oogenesis, for example, for germ cell proliferation; therefore, it is possible that homozygous mutant germ-line clones could not be recovered. For example, in addition to its role in the Der and Tor pathways, Ras-1 activity may also be required early in oogenesis for the proliferation and/or maturation of germ cells /C. Berg, pers. comm.). It is likely that ras-1 homozygous mutant germline clones generated by pole cell transplantations or by mitotic recombination would not be recovered.

Moreover, it may be difficult to look at the maternal homozygous mutant phenotype because of influences from the surrounding follicle cells. Although Tor and Der are required in different tissues of the female, they appear to activate signal transduction cascades that contain many common elements. For example, gap-1 mutations affect dorsoventral patterning in the follicular epithelium during oogenesis, which leads to the differentiation of dorsalized embryos /Gaul et al. 1992; $\mathrm{H}$. Ruohola-Baker, E. Grell, D. Baker, L.Y. Jan, and Y.N. Jan, in prep.). This phenotype appears to result from the overactivity of the Der signaling pathway in the follicle cells, which is transmitted to the embryo (Schüpbach 1987). Preliminary experiments indicate that a gap-1 mutation can enhance the tor ${ }^{R L 3}$ phenotype, suggesting that Gap-1 functions as a negative regulator in the Tor pathway $(\mathrm{H}$. Doyle, unpubl.l, as it does in the Sev and Der pathways \{Gaul et al. 1992; H. Ruohola-Baker, E. Grell, D. Baker, L.Y. Jan, and Y.N. Jan, in prep.). In addition, several of our Sultor) mutations partially affect the pattern of the chorion, implying that they too might act downstream of Der. Thus, the Der and Tor pathways show extensive overlap, though the ultimate targets are probably different. These maternal systems provide an elegant example of the economical use of signaling molecules: The cascades are activated in adjacent tissues, in the follicular epithelium during oogenesis, and in the egg after fertilization, by the stimulation of RTKs by ligands presumably originating in part from the other tissue.

\section{Model of the terminal system}

A summary of the terminal system signaling cascade is shown in Figure 8. Previous work has shown that trk, $f_{s}|1| p h, f_{s}(1 \mid N$, and $t s l$ act upstream of tor (Klingler 1989; Stevens et al. 1990). It is not known yet whether any of these genes encodes the ligand or whether any or all are involved in the spatial regulation of ligand production. Because some $f_{s}\{1) p h$ and $f_{s}(1) N$ alleles also give rise to unfertilized, collapsed eggs, their effects on the Tor pathway may be indirect (Degelmann et al. 1990). Of these maternal terminal-class genes, $t s I$ is the only one that is required in the follicle cells, specifically in those cells located at the anterior and posterior ends of the egg chamber (Stevens et al. 1990). Thus, tsl may play a key role in generating asymmetry in the terminal system.

Previous results and this study indicate that five known signaling proteins with homology to vertebrate proteins act downstream of Tor. Based loosely on analogy to other systems (Clark et al. 1992; Lowenstein et al. 1992; Wood et al. 1992), we have arranged these products in a signaling pathway, but it should be emphasized that there is no data yet addressing direct interactions between these proteins in the Tor pathway. Because the double mutant phenotype is stronger than either mutant alone, Perkins et al. (1992) suggested that Csw and Raf-1 act in parallel, rather than in a strictly linear pathway. Our preliminary results suggest that the pathway is not simply a cascade of positive interactions and that there are negative inputs, as gap-1 mutations and deficiencies of some regions appear to enhance the activity of the tor $^{R L 3}$ pathway (H. Doyle, unpub.).

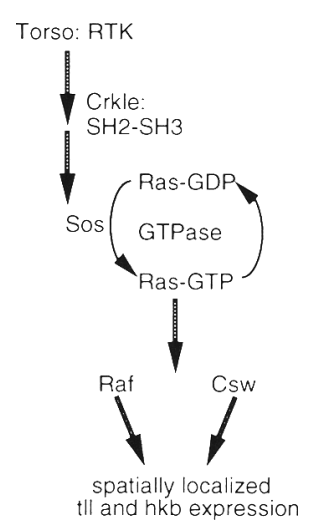

Figure 8. The Tor signal transduction pathway includes at least five known signaling molecules. It was shown previously that $1(1)$ ph, the Raf-1 homolog, and csw, a putative tyrosine phosphatase, are required in this pathway. Our results implicate the activity of three other recently identified signaling genesras-1; Sos, a guanine nucleotide exchange factor thought to interact with Ras; and $E[\operatorname{sev} \mid 2 B$ or $c r k-l e-$ which were first identified in the Sev pathway. The activities of these proteins are presented here in a model based partly on results from other systems, though we have not yet determined the epistatic relationships between these proteins in the Tor pathway. The end result of Tor activation is the transcription of the gap genes $t l l$ and $h k b$ in domains that are restricted to the poles of the embryo that give rise to terminal structures of the larvae. (For details and references, see discussion). 
It is probable that the earliest transcriptional targets of the Tor pathway are the zygotic gap genes $t I l$ and $h k b$ (Strecker et al. 1989; Pignoni et al. 1990; Brönner and Jäckle 1991; Steingrímsson et al. 1991). Spatially restricted expression of these genes is detected several nuclear cycles before cellular blastoderm formation, around the time of other gap gene expression. The transcription factors that regulate $t l l$ and $h k b$ expression are probably already present in the freshly fertilized egg and are activated, perhaps by phosphorylation, as the final step of Tor activation. Some of the other Sultor) genes identified in this screen may correspond to these proposed factors, as well as to other components of the Tor signaling pathway. We are currently pursuing a more extensive genetic and molecular investigation of several of these genes. Several of the apparently single-hit alleles are of particular interest because of their possible g-o-f or neomorphic effects.

We have shown that the Tor RTK pathway contains many components with homology to vertebrate growth control genes and oncogenes. Many of these important signaling components are recruited into signal transduction pathways in a variety of tissues throughout the development of the fly, including pathways activated by the RTKs Sev and Der. Thus far, it has not been determined where the specificity in these pathways lies, such that at the appropriate time and place, terminal larval structures or specific photoreceptors will differentiate in response to RTK activation. Further studies of these signaling mutations and the proteins they encode, as well as the identification of other components, will help elucidate the details of these critical signal transduction pathways.

\section{Materials and Methods}

Stocks

The markers and balancer chromosomes used are described in The Genome of Drosophila melanogaster (Lindsley and Zimm 1992). The tor ${ }^{R L 3}$ (also called spliced) and tor ${ }^{P M}$ alleles were obtained from Trudi Schüpbach (Schüpbach and Wieschaus 1989).

Approximately 200 homozygous $b$ pr tor ${ }^{R L 3} \mathrm{cn}$ males were treated with $35 \mathrm{~mm}$ ethylmethanesulfonate (EMS) in $1 \%$ sucrose for $24 \mathrm{hr}$ (Lewis and Bacher 1968). They were allowed to recover on standard fly media for $12 \mathrm{hr}$ before being mated with $\sim 1000$ tor $^{R L 3} \mathrm{cn} b \mathrm{w}$ homozygous females (see Fig. 2). The flies were allowed to mate and lay eggs at $18^{\circ} \mathrm{C}$. The parents were transferred to fresh bottles every $24 \mathrm{hr}$, and each bottle was kept at $18^{\circ} \mathrm{C}$ for $24 \mathrm{hr}$ after the parents were removed, to inhibit any g-o-f activity of tor ${ }^{R L 3}$, and then moved to $25^{\circ} \mathrm{C}$ until eclosion. All female progeny were collected as virgins, mated en masse to suitably marked males, and, after 1-2 days, placed into individual egg-laying blocks. We chose to do the screen at $27^{\circ} \mathrm{C}$ to eliminate background hatching and because the unsuppressed tor $^{R L 3}$ mutant phenotype is very consistent at this temperature. The eggs were collected for $24 \mathrm{hr}$ at $27^{\circ} \mathrm{C}$, and their phenotype was scored through the chorion under oil over a 3 -day period (the first collection was not scored to allow time for temperature equilibration). Embryo collections in which $>50 \%$ of the embryos showed two or more abdominal denticle belts were considered to be suppressed. Females that produced embryos showing a suppressed phenotype in two $24-\mathrm{hr}$ collections were removed from the blocks and placed in fresh vials at $18^{\circ} \mathrm{C}$. Progeny were recovered, and individual balanced lines were established. A secondary screen was done to determine the chromosomal linkage of the putative Su(tor) loci and to eliminate non* reproducible effects. Fifteen thousand individual females were screened, and 160 suppressors were identified in the primary screen. Of these, 130 gave viable progeny. Individual stocks were established by the strategy outlined in Figure 2 . They were screened once again using cuticle preparations and then reduced to 45 lines.

The tor $^{R L 3}$ mutation is closely linked ( $<0.5 \%$ recombination) to the visible eye color gene, $\mathrm{cn}$. In all subsequent crosses we could follow the tor ${ }^{R L 3}$ gene by looking for $\mathrm{cn}$. This was important because we needed to rescreen and map the Su(tor) mutations in the presence of tor $^{R L 3}$.

\section{Recombination mapping}

Several of the strong Su(tor) mutations located on the second chromosome were initially mapped very roughly using a second chromosome containing the dominant markers with $S$ Sp BI Tft $L$. Individual recombinant females that were homozygous for $\operatorname{tor}^{R L 3}$ (i.e., $\mathrm{cn} / \mathrm{cn}$ ) were assayed for suppressed embryos. In this way, a rough map position relative to tor was obtained. In most cases, several recombinant chromosomes were backcrossed to the original Su(tor) stock to see whether the suppressor could be separated from the lethality. Those stocks in which the suppressor and the lethal seemed to be closely linked were mapped more accurately as lethals, independent of their affect on $t o r^{R L 3}$. The stocks with more than one lethal allele were mapped first as suppressors and than as lethals using the independent alleles. For these finer mapping studies, the multiply marked second chromosome $a l d p b$ pr $c p x s p$ was used with the tester chromosome $a l d p b$ pr $B l c p x s p$. The map positions of the mutations for which a large number of recombinants were obtained are given in approximate recombination units in Table 1 , whereas those for which fewer recombinants were obtained are shown only relative to visible markers.

The Sultor) mutations linked to the third chromosome were more difficult to map as suppressors in a homozygous tor ${ }^{R L 3}$ background. We therefore only attempted to map the two lethal complementation groups, $S u(t o r \mid 3-1$ and Sultor|3-2, making the assumption that the lethality and suppressor mapped together. Recombinant lethal chromosomes that were retested for their ability to suppress tor $^{R L 3}$ confirmed this assumption. The Sultor|3-2 mutations were found to be alleles of ras-1, so the recombination mapping was not continued. We initially mapped the lethality of $S u(t o r \mid 3-1$ between st and $c u$, using the chromosome marked ru h th st cu sr $e^{s} \mathrm{ca}$. We then mapped these mutations using the $m w h$ th st ri roe $p^{p} c u$ sr $e^{s}$ chromosome to lie at $\sim 3-48$. Because of the difficulty in mapping the third chromosome-linked mutations in a homozygous tor ${ }^{R L 3}$ background, the other mutations were not mapped.

As indicated in Table 1, one female sterile complimentation group, Sultor|1-1, was linked to the $\mathrm{X}$ chromosome. Homozygous females carrying any combination of these four alleles produce eggs with discolored and collapsed chorions. We used this female sterile phenotype to map this mutation to a position roughly between $c v$ and $c t$, at approximately map position 18-19.

\section{Cuticle and chorion preparations}

Cuticle preparations were done in Hoyers medium as described (Wieschaus and Nüsslein-Volhard 1986) and examined using dark-field microscopy. The vitelline membranes were removed 
either by pressing on the coverslip or by shaking in a mixture of heptane and methanol before mounting in Hoyers. Embryos displaying a strong $t o r^{R L 3}$ mutant phenotype collapse when the vitelline membrane is removed, so this membrane was left intact in some preparations. Eggs with chorions were gently rinsed from egg collection plates and mounted directly in Hoyers without fixation.

\section{Whole-mount in situ hybridization}

The $t 11$ cDNA clone was obtained from Pignoni et al. (1990), and the insert was labeled with digoxigenin-dUTP by random priming (Boehringer-Mannheim). Embryos were prepared for wholemount in situ hybridization as described previously (Tautz and Pfeifle 1989), and the signal was detected using the Genius Kit (Boehringer-Mannheim).

\section{$S E M$}

Adult wild-type or heterozygous Elp females with or without a Sultor| mutation were dehydrated and prepared for SEM as described previously (Kimmel et al. 1990).

\section{Acknowledgments}

This work was supported by National Institutes of Health grant to J.M.B (CA 44338) and by funds from the G.W. Hooper Research Foundation. H.D. was supported by postdoctoral fellowships from the European Molecular Biology Organization and the American Cancer Society. This work was initiated in the laboratory of Christiane Nüsslein-Volhard at the Max Planck Insitut für Entwicklungsbiologie in Tübingen, and H.D. thanks many colleagues there for encouragement and stimulating discussions, in particular Leslie Stevens and Daniel St. Johnston, and also Suzanne Wendler for technical help and Martin Klingler and Trudi Schüpbach for fly stocks. We thank Suzanne Eaton, Trudi Schüpbach, Pascal Therond, Vivian Siegel, Leslie Stevens, and Manfred Frasch for valuable comments on the manuscript.

The publication costs of this article were defrayed in part by payment of page charges. This article must therefore be hereby marked "advertisement" in accordance with 18 USC section 1734 solely to indicate this fact.

\section{Note added in proof}

The name of the gene crk-le has apparently been changed to $d r k$, or downstream of regulated kinase (G.M. Rubin, pers. comm.).

\section{References}

Ambrosio, L., A.P. Mahowald, and N. Perrimon. 1989a. 1(1)pole hole is required maternally for pattern formation in the terminal regions of the embryo. Development 106: 145-158.

- 1989b. Requirement of the Drosophila raf homologue for torso function. Nature 342: 288-291.

Aroian, R.V., M. Koga, J.E. Mendel, Y. Ohshima, and P.W. Sternberg. 1990. The let-23 gene necessary for Caenorhabditis elegans vulval induction encodes a tyrosine kinase of the EGF receptor subfamily. Nature 348: 251-267.

Baker, N.E. and G.M. Rubin. 1989. Effect on eye development of dominant mutations in the Drosophila homolog of the EGF receptor. Nature 340: 150-153.

Basler, K., B. Christen, and E. Hafen. 1991. Ligand-independent activation of the sevenless receptor tyrosine kinase changes the fate of cells in the developing Drosophila eye. Cell 64: 1069-1081.

Beitel, G.J., S.G. Clark, and H.R. Horvitz. 1990. Caenorhabditis elegans ras gene let- 60 acts as a switch in the pathway of vulval induction. Nature 348: 503-509.

Berleth, T., B.M., G. Thoma, D. Bopp, S. Richstein, G. Frigerio, M. Noll, and C. Nüsslein-Volhard. 1988. The role of localization of bicoid RNA in organizing the anterior pattern of the Drosophila embryo. EMBO 1. 7: 1749-1756.

Bonfini, L., C.A. Karlovich, C. Dasgupta, and U. Baneriee. 1992. The Son of Sevenless gene product: A putative activator of Ras. Science 255: 603-606.

Bourne, H.R., D.A. Sanders, and F. McCormick. 1991. The GTPase superfamily: Conserved structure and molecular mechanism. Nature 349: 117-127.

Brock, H.W. 1987. Sequence and genomic structure of ras homologues Dmras85D and Dmras64B of Drosophila melanogaster. Gene 51: 129-137.

Brönner, G. and H. Jäckle. 1991. Control and function of terminal gap gene activity in the posterior pole region of the Drosophila embryo. Mechanisms of Dev. 35: 205-211.

Cantley, L.C., K.R. Auger, C. Carpenter, B. Duckworth, A. Graziani, R. Kapellar, and S. Soltoff. 1991. Oncogenes and signal transduction. Cell 64: 281 302 .

Casanova, J. and G. Struhl. 1989. Localized surface activity of torso, a receptor tyrosine kinase, specifies terminal body pattern in Drosophila. Genes \& Dev. 3: 2025-2038.

Chant, J., K. Corrado, J.R. Pringle, and I. Herskowitz. 1991. Yeast BUD5, encoding a putative GDP-GTP exchange factor, is necessary for bud site selection and interacts with bud formation gene BEM1. Cell 65: 1213-1224.

Clark, S.G., M.J. Stern, and H.H. Robert. 1992. C. elegans cellsignaling gene sem-5 encodes a protein with $\mathrm{SH} 2$ and $\mathrm{SH} 3$ domains. Nature 356: 340-344.

Degelmann, A., P.A. Hardy, and A.P. Mahowald. 1990. Genetic analysis of two female-sterile loci affecting eggshell integrity and embryonic pattern formation in Drosophila melanogaster. Genetics 126: 427-434.

Driever, W. and C. Nüsslein-Volhard. 1988. The bicoid protein determines position in the Drosophila embryo in a concentration-dependent manner. Cell 54: 95-104.

Fortini, M.E., M.A. Simon, and G.M. Rubin. 1992. Signaling by the sevenless protein tyrosine kinase is mimicked by Ras 1 activation. Nature 355: 559-561.

Gaul, U., G. Mardon and G.M. Rubin. 1992. A putative Ras GTPase activating protein acts as a negative regulator of signaling by the Sevenless receptor tyrosine kinase. Cell 68: 1007-1019.

Greenwald, I. and G.M. Rubin. 1992. Making a difference: The role of cell-cell interactions in establishing separate identities for equivalent cells. Cell 68: 271-281.

Hariharan, I.K., R.W. Carthew, and G.M. Rubin. 1991. The Drosophila Roughened mutation: Activation of a rap homolog disrupts eye development and interferes with cell determination. Cell 67: 717-722.

Hill, R. J. and P.W. Sternberg. 1992. The gene lin-3 encodes an inductive signal for vulval development in C. elegans. Nature 358: $470-476$.

Kimmel, B.E., U. Heberlein, and G.M. Rubin. 1990. The homeo domain protein rough is expressed in a subset of cells in the developing Drosophila eye where it can specify photoreceptor cell subtype. Genes \& Dev. 4: 712-727.

Klingler, M. 1989. Die Funktion des Genes torso bei der Determination terminaler Anlagen im Drosophila Embryo. Eberhard-Karls-Universität, Tübingen, Germany.

Klingler, M., M. Erdélyi, J. Szabad, and C. Nüsslein-Volhard. 
1988. Function of torso in determining the terminal anlagen of the Drosophila embryo. Nature 335: 275-277.

Lehmann, R. and C. Nüsslein-Volhard. 1986. Abdominal segmentation, pole cell formation, and embryonic polarity require the localized activity of oskar, a maternal gene in Drosophila. Cell 47: 141-152.

Lewis, E.B. and F. Bacher. 1968. Method of feeding ethyl methane sulfonate (EMS) to Drosophila males. Dros. Inf. Ser. 43: 193.

Lindsley, D.L. and G.G. Zimm 1992. The Genome of Drosophila melanogaster. Academic Press, San Diego, CA.

Lowenstein, E.J., R.J. Daly, A.G. Batzer, B. Margolis, R. Lammers, A. Ullrich, E.Y. Skolnik, D. Bar-Sagi, and J. Schlessinger. 1992. The SH2 and SH3 domain-containing protein GRB2 links receptor tyrosine kinases to ras signaling. Cell 70: $431-442$.

Margolis, B. 1992. Proteins with SH2 SH3 domains: Transducers in the tyrosine kinase signaling pathway. Cell Growth Differ. 3: 73-80.

Mark, G.E., R.J. MacIntyre, M.E. Digan, L. Ambrosio, and N. Perrimon. 1987. Drosophila melanogaster homologs of the raf oncogene. Mol. Cell. Biol. 7: 2134-2140.

Mayer, B.J., M. Hamaguchi, and H. Hanafusa. 1988. A novel viral oncogene with structural similarity to phospholipase C. Nature 332: 272-275.

Neuman-Silberberg, F.S., E. Schejter, F.M. Hoffman, and B.Z. Shilo. 1984. The Drosophila ras oncogenes: Structure and nucleotide sequence. Cell 37: 1027-1033.

Nishida, Y., M. Hata, T. Ayaki, H. Ryo, M. Yamagata, K. Shimizu, and Y. Nishizuka. 1988. Proliferation of both somatic and germ cells is affected in the Drosophila mutants of raf proto-oncogene. EMBO /. 7: 775-781.

Nüsslein-Volhard, C., H.G. Frohnhöfer, and R. Lehmann. 1987. Determination of anterior-posterior polarity in Drosophila. Science 238: 1675-1681.

Pawson, T. 1992. Signal transduction in the control of cell growth and development. Trends Genet. 7: 343-345.

Perkins, L.A., I. Larsen, and N. Perrimon. 1992. corkscrew encodes a putative protein tyrosine phosphatase that functions to transduce the terminal signal from the receptor tyrosine kinase torso. Cell 70: 225-236.

Perrimon, N., L. Engstrom, and A.P. Mahowald. 1985. A pupal lethal mutation with a paternally influenced maternal effect on embryonic development in Drosophila melanogaster. Dev Biol. 110: 480-491.

Pignoni, F., R.M. Baldarelli, E. Steingrimisson, R.J. Diaz, A. Patapoutian, J.R. Merriam, and J.A. Lengyel. 1990. The Drosophila gene tailless is expressed at the embryonic termini and is a member of the steroid receptor superfamily. Cell 62: 151-163.

Powers, S., E. Gonzalez, T. Christensen, J. Cubert, and D. Broek. 1991. Functional cloning of BUD5, a CDC25-related gene from $S$. cerevisiae that can suppress a dominant-negative RAS2 mutant. Cell 65: 1225-1231.

Price, I.V., R.J. Clifford, and T. Schüpbach. 1989. The maternal ventralizing locus torpedo is allelic to faint little ball, an embryonic lethal, and encodes the Drosophila EGF receptor homolog. Cell 56: 1085-1092.

Rogge, R.D., C.A. Karlovich, and U. Banerjee. 1991. Genetic dissection of a neurodevelopmental pathway: Son of sevenless functions downstream of the sevenless and EGF receptor tyrosine kinases. Cell 64: 39-48.

Rubin, G.M. 1991. Signal transduction and the fate of the R7 photoreceptor in Drosophila. Trends Genet. 7: 372-377.

Schejter, E.D. and B.-Z. Shilo. 1989. The Drosophila EGF receptor homolog (Der) gene is allelic to faint little ball, a locus essential for embryonic development. Cell 56: 1093-1104.

Schüpbach, T. 1987. Germ line and soma cooperate during oogenesis to establish the dorsoventral pattern of egg shell and embryo in Drosophila melanogaster. Cell 49: 699-707.

Schüpbach, T. and E. Wieschaus. 1989. Female sterile mutations on the second chromosome of Drosophila melanogaster. I. Maternal effect mutations. Genetics 121: 101-117.

Simon, M.A., D.D.L. Bowtell, G.S. Dodson, T.R. Laverty, and G.M. Rubin. 1991. Rasl and a putative guanine nucleotide exchange factor perform crucial steps in signaling by the sevenless tyrosine kinase. Cell 67: 701-716.

Simon, M.A., R.W. Carthews, M.E. Fortini, U. Gaul, G. Mardon, and G.M. Rubin. 1993. Signal transduction pathway initiated by activation of the sevenless tyrosine kinase receptor. Cold Spring Harbor Symp. Quant. Biol. 57: 375-380.

Sprenger, F., L.M. Stevens, and C. Nüsslein-Volhard. 1989. The Drosophila gene torso encodes a putative receptor tyrosine kinase. Nature 338: 478-483.

St. Johnston, D. and Nüsslein-Volhard. 1992. The origin of pattern and polarity in the Drosophila embryo. Cell 68: 201219.

Stein, D.S. and L.M. Stevens. 1991. Establishment of dorsalventral and terminal pattern in the Drosophila embryo. Curr. Opin. Genet. Dev. 1: 247-254.

Stein, D., S. Roth, E. Vogelsang, and C. Nüsslein-Volhard. 1991. The polarity of the dorsoventral axis in the Drosophila embryo is defined by an extracellular signal. Cell 65: 725 735 .

Steingrímsson, E., F. Pignoni, G. Liaw, and J. Lengyel. 1991. Dual role of the Drosophila pattern gene tailless in embryonic termini. Science 254: 418-421.

Sternberg, P.W. and H.R. Horvitz. 1992. Signal transduction during C. elegans vulval induction. Trends Genet. 7: 366371.

Stevens, L.M., H.G. Frohnhöfer, M. Klingler, and C. Nus̈sleinVolhard. 1990. Localized requirement for torso-like expression in follicle cells for development of terminal anlagen of the Drosophila embryo. Nature 346: 660-663.

Strecker, T.R., S.R. Halsell, W.W. Fisher, and H.D. Lipshitz. 1989. Reciprocal effects of hyper- and hypoactivity mutations in the Drosophila pattern gene torso. Science 243: 1062-1066.

Tautz, D. and C. Pfeifle. 1989. A non-radioactive in situ hybridization method for the localization of specific RNAs in Drosophila reveals translational control of the segmentation gene hunchback. Chromosoma 98: 81-85.

Wang, C. and R. Lehmann. 1991. nanos is the localized posterior determinant in Drosophila. Cell 66: 637-647.

Wieschaus, E. and C. Nüsslein-Volhard 1986. Looking at embryos. In Drosophila: A practical approach, pp. 199-227. IRL Press, Washington, D.C.199-227.

Wood, K.W., C. Sarnecki, T.M. Roberts, and J. Blenis. 1992. ras mediates nerve growth factor receptor modulation of three signal-transducing kinases: MAP kinase, Raf-1, and Rsk. Cell 68: 1041-1050. 


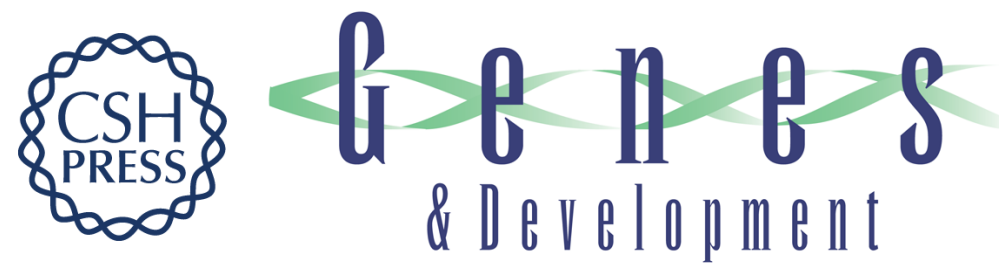

\section{Torso, a receptor tyrosine kinase required for embryonic pattern formation, shares substrates with the sevenless and EGF-R pathways in Drosophila.}

H J Doyle and J M Bishop

Genes Dev. 1993, 7:

Access the most recent version at doi:10.1101/gad.7.4.633

References This article cites 57 articles, 10 of which can be accessed free at: http://genesdev.cshlp.org/content/7/4/633.full.html\#ref-list-1

License

Email Alerting Service

Receive free email alerts when new articles cite this article - sign up in the box at the top right corner of the article or click here.

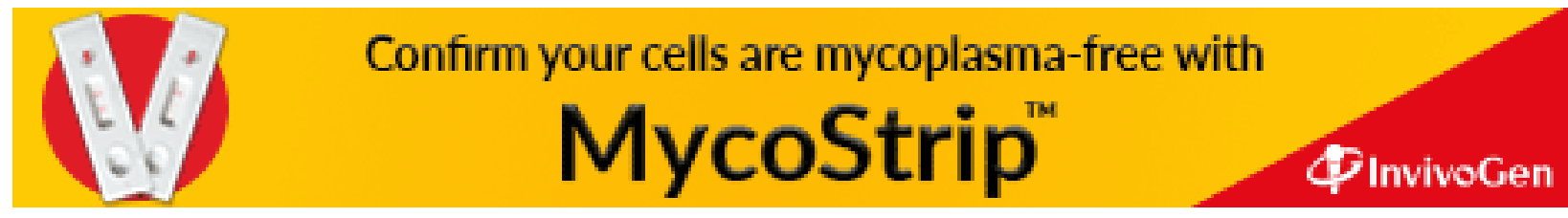

